\title{
Underwater endoscopic mucosal resection: a new endoscopic method for resection of rectal neuroendocrine tumor grade 1 (carcinoid) $\leq 10 \mathrm{~mm}$ in diameter $\square$
}

(1) $\odot \ominus$

\author{
Authors \\ Takeshi Yamashina, Takehiko Tumura, Takanori Maruo, Takayuki Matsumae, Hiroyuki Yoshida, Gensho Tanke, Mio \\ Taki, Manabu Fukuhara, Yoshito Kimura, Azusa Sakamoto, Shinichiro Henmi, Yugo Sawai, Sumio Saito, Norihiro \\ Nishijima, Akihiro Nasu, Hideyuki Komekado, Masanori Asada, Ryuichi Kita, Toru Kimura, Yukio Osaki
}

Institution

Department of Gastroenterology and Hepatology, Osaka Red Cross Hospital, Osaka, Japan

submitted 17.8 .2017

accepted after revision 10.11 .2017

Bibliography

DOI https://doi.org/10.1055/s-0043-123467 |

Endoscopy International Open 2018; 06: E111-E114

(c) Georg Thieme Verlag KG Stuttgart · New York ISSN 2364-3722

Corresponding author

Takeshi Yamashina, Department of Gastroenterology and Hepatology, Osaka Red Cross Hospital, 5-30 Fudegasakicho, Tenouji-ku, Osaka 543-8555, Japan

Fax: +81-6-6774-5131

take8047@hotmail.com

\section{ABSTRACT}

Background and study aims Rectal neuroendocrine tumors grade 1 (NET G1; carcinoid) $\leq 10 \mathrm{~mm}$ in diameter often extend into the submucosa, making their complete histological resection difficult using endoscopic techniques. Endoscopic submucosal resection with a ligation device (ESMR-L) and endoscopic submucosal dissection (ESD) are commonly used to overcome these difficulties. We also previously reported that underwater endoscopic mucosal resection (UEMR) could facilitate resection of rectal NET G1. This study aimed to evaluate the safety and efficacy of UEMR for removing rectal NET G $1 \leq 10 \mathrm{~mm}$ in diameter. 6 consecutive patients with rectal NET G $1 \leq 10 \mathrm{~mm}$ in diameter underwent UEMR at our hospital. The rate of en bloc resection was $100 \%$, and the rate of R0 resection was $83 \%$. The median procedure time was $8 \mathrm{~min}$ (range $5-12 \mathrm{~min}$ ). No perforations or delayed bleeding occurred in this study. In conclusion, UEMR allows the safe and reliable resection of rectal NET G1 $\leq 10 \mathrm{~mm}$ in diameter with comparable results to ESMR-L or ESD, including high en bloc and R0 resection rates with no increase in significant adverse events. A multicenter trial is required to confirm the validity of the present results.

\section{Introduction}

Endoscopic resection of rectal neuroendocrine tumor grade 1 (NET G1; carcinoid) $\leq 10 \mathrm{~mm}$ in diameter is commonly performed in the clinical setting. However, despite the existence of various endoscopic resection methods, it is difficult to achieve complete histological resection of rectal NET G1 because most extend to the submucosa [1]. Several novel methods have been reported to overcome the difficulties associated with resecting the submucosal layer under the tumor, such as endoscopic submucosal resection with a ligation device (ESMR-L) [2] and endoscopic submucosal dissection (ESD) [3]. We also previously reported that underwater endoscopic mucosal resection (UEMR) could facilitate the resection of rectal NET G1 [4]. UEMR is a new technique for removing flat colorec- tal lesions, first described by Binmoeller et al. [5], in which the bowel lumen is filled with water rather than air, and the lesion is then resected without submucosal injection. Some studies reported that UEMR was a safe and effective procedure for removing flat colorectal polyps [5,6]. However, to the best of our knowledge, only 2 cases of UEMR for colorectal submucosal tumors have been reported [4,7]. This study aimed to evaluate the safety and efficacy of UEMR for removing rectal NET G1 $\leq 10 \mathrm{~mm}$ in diameter. 
- Table 1 Patient and treatment characteristics

\begin{tabular}{|c|c|c|c|c|c|c|c|c|c|c|}
\hline Case & $\begin{array}{l}\text { Age } \\
\text { (years } \\
\text { old) }\end{array}$ & Gender & $\begin{array}{l}\text { NET G1 } \\
\text { location }\end{array}$ & $\begin{array}{l}\text { NET G1 size/ } \\
\text { resected size } \\
(\mathrm{mm})\end{array}$ & $\begin{array}{l}\text { Procedure } \\
\text { time } \\
\text { (minutes) }\end{array}$ & $\begin{array}{l}\text { Resec- } \\
\text { tion }\end{array}$ & Margin & $\begin{array}{l}\text { Lymphovascular } \\
\text { involvement }\end{array}$ & $\begin{array}{l}\text { Depth of } \\
\text { tumor }\end{array}$ & $\begin{array}{l}\text { Endos- } \\
\text { copist }\end{array}$ \\
\hline 1 & 24 & Female & $\mathrm{Rb}$ & $4 / 5$ & 7 & En bloc & negative & negative & Submucosal & B \\
\hline 2 & 47 & Female & $\mathrm{Ra}$ & $5 / 6$ & 5 & En bloc & negative & negative & Intramucosal & $A$ \\
\hline 3 & 58 & Male & $\mathrm{Ra}$ & $5 / 6$ & 12 & En bloc & VM positive & negative & Submucosal & A \\
\hline 4 & 63 & Male & $\mathrm{Rb}$ & $9 / 10$ & 9 & En bloc & negative & negative & Submucosal & $B$ \\
\hline 5 & 79 & Male & $\mathrm{Rb}$ & $10 / 13$ & 10 & En bloc & negative & negative & Submucosal & C \\
\hline 6 & 53 & Female & $\mathrm{Rb}$ & $6 / 10$ & 6 & En bloc & negative & negative & Submucosal & A \\
\hline
\end{tabular}

NET G1, neuroendocrine tumor grade 1; Rb, rectum below the peritoneal reflection; Ra, rectum above the peritoneal reflection; VM, vertical margin.

\section{Case Reports}

\section{Patients and methods}

This study was performed at Osaka Red Cross Hospital. 6 consecutive patients with rectal NET G1 $\leq 10 \mathrm{~mm}$ in diameter were included between March 2016 and June 2017. The main outcomes of this study were en bloc resection rate, $\mathrm{R} 0$ resection rate, and complications. All patients in this study were evaluated by endoscopic ultrasonography to confirm that the tumor was $\leq 10 \mathrm{~mm}$ in diameter, and that the tumor was located in the muscularis mucosae or submucosa before UEMR.

\section{UEMR procedure}

The UEMR procedure was performed as described previously [4]. All procedures were carried out using a colonoscope (CFHQ290, PCF-PQ260 L, Olympus Medical Systems, Tokyo, Japan). Electrical cutting and coagulation was carried out using a VIO 300D (ERBE Elektromedizin, Tübingen, Germany) power

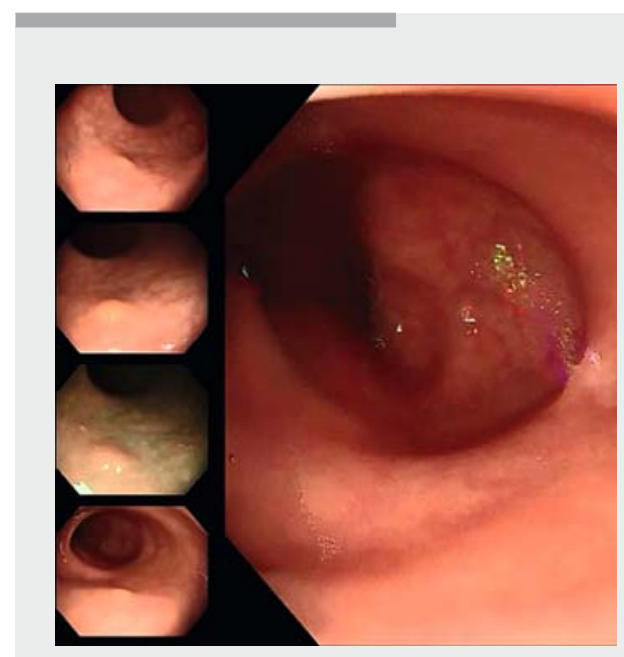

Video 1 Underwater EMR showed an approximately 8-mm-diameter yellow-white submucosal tumor in the rectum and a pseudopedicle of the neuroendocrine tumor created by water emersion, facilitating easy excision of the tumor. source. The UEMR procedure employed a polypectomy snare (DRAGONARETM , Xemex, Tokyo, Japan). The rectum lumen was completely deflated and the tumor was totally immersed in water using a water pump (OFP-2; Olympus) to elevate the tumor. The tumor was then snared, together with the surrounding normal mucosa, and resected ( $\vee$ Video 1 ). The mucosal defect was then closed using endoscopic clips. The procedure time was measured from the initial immersion in water until complete closure of the mucosal defect. All patients consumed a soft meal the following day and remained in hospital for 2 days. All patients underwent a postoperative follow-up hospital visit about 2 weeks after polypectomy.

\section{Results}

6 consecutive patients with rectal NET G $1 \leq 10 \mathrm{~mm}$ in diameter underwent UEMR at our hospital during the study period. The baseline characteristics are presented in $>$ Table 1 . There were 3 men and 3 women, with a median age (range) of 70 (47-86) years. 4 NET G1 were located in the rectum below the peritoneal reflection and 2 above the peritoneal reflection. The median tumor size was $5.5 \mathrm{~mm}$ (range $4-10 \mathrm{~mm}$ ). The UEMR procedures were performed by 3 fully-trained endoscopists ( $A, B$, and $C)$; surgeons' endoscopic experience is shown in $>$ Table 2 . The rate of en bloc resection was $100 \%(6 / 6)$, and 1 patient had a positive vertical margin; the rate of R0 resection was $83 \%$ (5/ $6)$. The mucosal defect was closed using clips in all cases. The median procedure time was $8 \mathrm{~min}$ (range 5-12 min). All cases were diagnosed as a NET G1 (carcinoid) by pathological examination. No perforations or delayed bleeding occurred in this study. 6 months later, we performed follow-up colonoscopy in a non-R0 resection patient and found a UEMR scar without residual tumor.

\section{Discussion}

In this study, UEMR for rectal NET G1 $\leq 10 \mathrm{~mm}$ in diameter achieved a high en bloc resection rate of $100 \%$ and $\mathrm{R} 0$ resection rate of $83 \%$, without adverse events. This success was associated with the creation by UEMR of a pseudopedicle, allowing the 
- Table 2 Endoscopic experience of each endoscopist.

\begin{tabular}{|l|l|l|l|}
\hline & $\begin{array}{l}\text { Endoscope experience } \\
\text { before study }\end{array}$ & $\begin{array}{l}\text { Endoscopic resection } \\
\text { experience before study }\end{array}$ & UEMR experience before study \\
\hline Endoscopist A & $\begin{array}{l}\text { EGD: } \geq 10,000 \\
\text { CS: } \geq 5,000\end{array}$ & $\geq 2,000$ & 230 \\
\hline Endoscopist B & $\begin{array}{l}\text { EGD: } \geq 13,000 \\
\text { CS: } \geq 7,000\end{array}$ & $\geq 3,000$ & 5 \\
\hline Endoscopist C & EGD: $\geq 15,000$ & 0 \\
\hline CS: $\geq 10,000$ & & \\
\hline EGD, esophagogastroduodenoscopy; $C S$, colonoscopy; UEMR, underwater endoscopic mucosal resection.
\end{tabular}
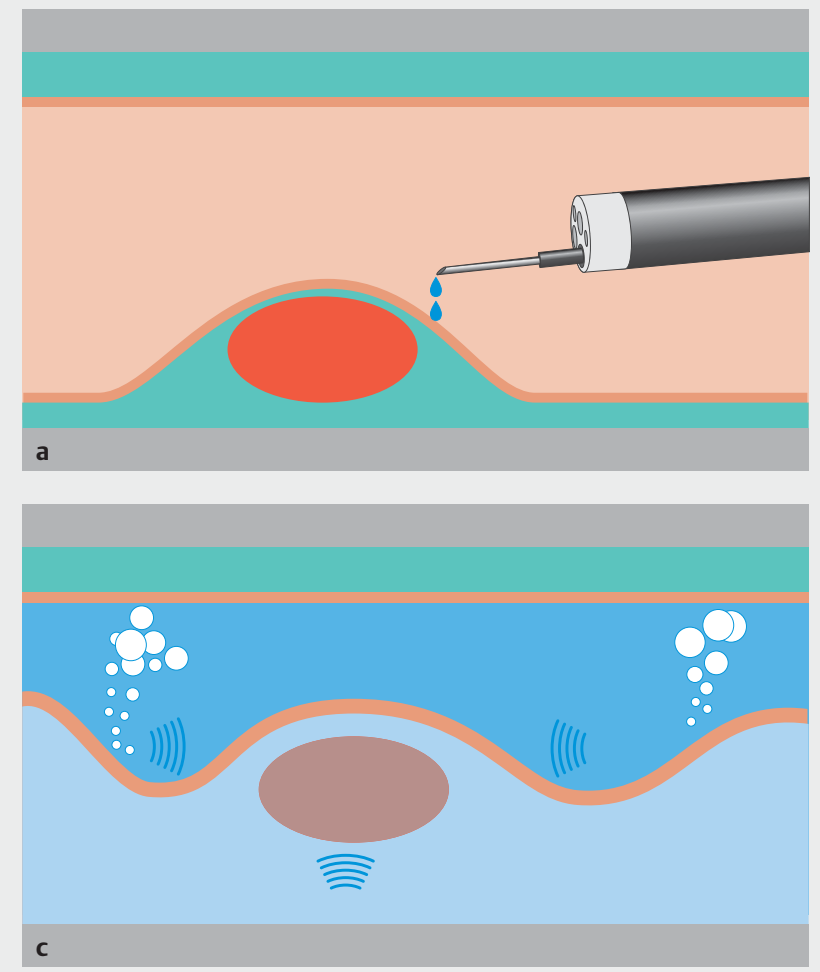
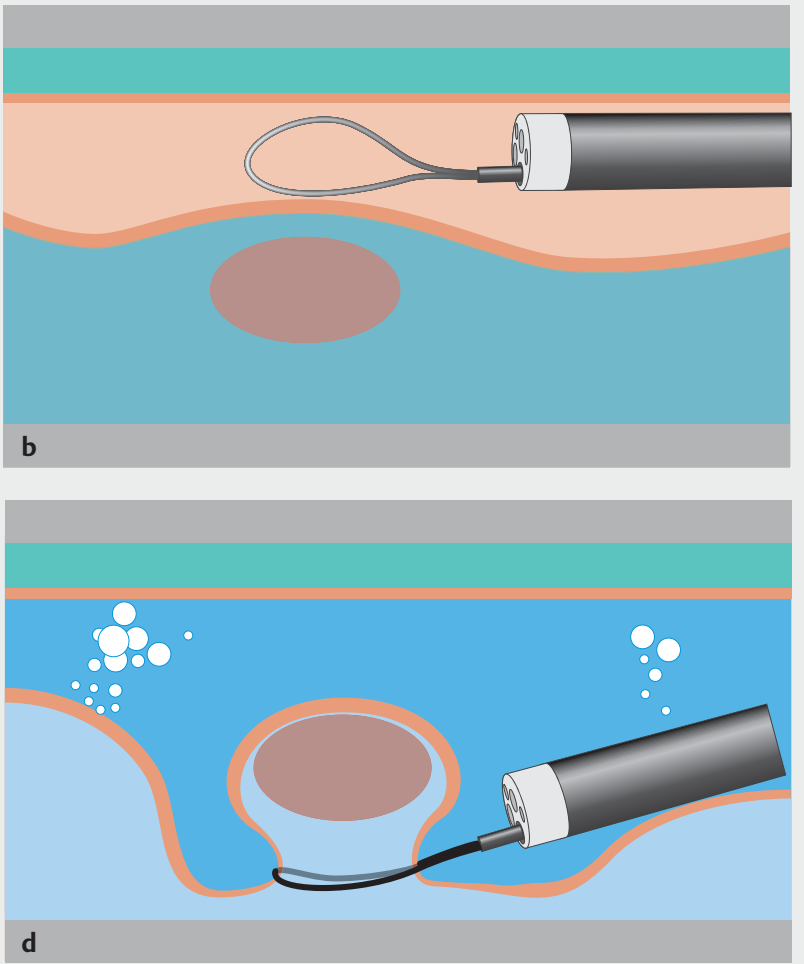

- Fig. 1 a Lifting the submucosa by injection in a conventional EMR case. $\mathbf{b}$ Inappropriate injection makes it difficult to snare the tumor. c Deflating the air and immersion under water lift and float away submucosal tumor from the muscularis propria. $\mathbf{d}$ A pseudopedicle allows the operator to more easily snare the submucosal tumor.

safe and rapid resection of the tumor. Conventional EMR is a technique that involves lifting the submucosa by injection; however, inappropriate injection can make it difficult to capture the submucosal tumor with the snare ( $>$ Fig.1a and - Fig. 1b). To obtain reliable resection, we believe it is important to separate submucosal tumors from the muscularis propria. The underwater technique likely increases the buoyancy of submucosal tumors, which lift and float away from the muscularis propria. Also, deflating the air loosens the mucosal folds, which creates pseudopedicles that allow the operator to more easily snare the submucosal tumors ( $\triangleright$ Fig.1c and $\triangleright$ Fig.1d). ESMR-L uses injection and a ligation device to separate the mucosa from the muscularis propria, which also makes it easier to snare submucosal tumors. We consider ESMR-L similar to UEMR in that the former uses a lift-and-cut method.

The median procedure time, from immersion in water to defect closure, was only $8 \mathrm{~min}$. Although several endoscopic resection methods are available for rectal NET G1, including ESMR-L [2] and ESD [3], these techniques are associated with high costs and effort. ESD is a promising treatment for large, superficial colorectal neoplasms, with a high en bloc resection rate, but its mean procedure time for rectal NET G1 was longer than that of ESMR-L [3]. In contrast, UEMR is also faster than $E S D$, and does not require specialized equipment compared with ESD and ESMR-L, such as endo-knives or ligation devices. Furthermore, UEMR is easy for experienced endoscopists to 
learn. On the other hand, the underwater technique makes it somewhat difficult to see the tumor because of the narrowed lumen, and inadequate bowel preparation, oozing, or chromoendoscopy increase this difficulty. In these situations, endoscopists must take more care when snaring.

Histologically complete resection rates of $28.6 \%$ to $100 \%$ have been reported for conventional polypectomy or EMR for rectal NET G1 [2]. In addition, some studies reported R0 resection rates as high as $82.8 \%$ to $100 \%$ with ESMR-L $[2,8,9]$, and $80.6 \%$ to $100 \%$ with $\operatorname{ESD}[3,8,9]$. However, 1 of the main reasons for the difficulties encountered during endoscopic resection of NET G1 is that most of them extend to the submucosa [1], necessitating resection of the submucosal layer under the NET. Binmoeller et al. reported that immersion in water in the colon lumen caused the muscularis propria to adopt a spherical shape, and the mucosa and submucosa to float away from the muscularis propria, leading to less risk of accidentally cutting the muscularis propria. We therefore considered that UEMR could allow resection of the submucosal layer under the NET in rectal NET G1 $\leq 10 \mathrm{~mm}$ in diameter, leading to high $\mathrm{R} 0$ resection rates with no risk of perforation.

Accordingly, there were no cases of perforation or bleeding in the current study. Although, ESMR-L and ESD may achieve higher $\mathrm{R} 0$ resection rates than conventional polypectomy or EMR, the perforation rate of ESD for rectal NET G1 was previously reported as $2.2 \%$ [3]. Although there has been 1 report of perforation during UEMR [10], the procedure in this case was performed in a retroflex position, leading to colonic wall thinning due to additional stress on the colonic wall. This would not normally be an issue in the case of UEMR for rectal NET G1, because endoscopists pay close attention to any stress on the colonic wall.

1 limitation of our study was that it was a single-center study with few patients. Further multicenter studies are required in larger numbers of patients, including comparisons between UEMR and other methods.

In conclusion, UEMR allows the safe and reliable resection of rectal NET G1 $10 \mathrm{~mm}$ in diameter. It demonstrates comparable results to ESMR-L or ESD, including high en bloc and R0 resection rates with no increase in significant adverse events. A multicenter trial is required to confirm the validity of the present results.

\section{Acknowledgements}

The authors thank all endoscopists and our colleagues at the Department of Gastroenterology and Hepatology, Osaka Red Cross Hospital, who supported this study.

\section{Competing interests}

None

References

[1] Soga J. Carcinoids of the rectum: an evaluation of 1271 reported cases. Surg Today 1997; 27: 112-119

[2] Mashimo Y, Matsuda T, Uraoka T et al. Endoscopic submucosal resection with a ligation device is an effective and safe treatment for carcinoid tumors in the lower rectum. J Gastroenterol Hepatol 2008; 23: $218-221$

[3] Lee DS, Jeon SW, Park SY et al. The feasibility of endoscopic submucosal dissection for rectal carcinoid tumors: comparison with endoscopic mucosal resection. Endoscopy 2010; 42: 647-651

[4] Marui S, Yamashina T, Henmi S et al. A New Endoscopic Resection Method for Rectal Carcinoid Tumor: Underwater Endoscopic Mucosal Resection. Glob J Gastroenterol Hepatol 2016; 4: 24-25

[5] Binmoeller KF, Weilert F, Shah J et al. "Underwater"; EMR without submucosal injection for large sessile colorectal polyps (with video). Gastrointest Endosc 2012; 75: 1086 - 1091

[6] Uedo N, Nemeth A, Johansson GW et al. Underwater endoscopic mucosal resection of large colorectal lesions. Endoscopy 2015; 47: $172-$ 174

[7] Kawaguti FS, de Oliveira JF, da Costa Martins B et al. Underwater endoscopic resection of a neuroendocrine rectal tumor. Endoscopy 2015; 47: E513-E514

[8] Harada H, Suehiro S, Murakami D et al. Endoscopic submucosal dissection for small submucosal tumors of the rectum compared with endoscopic submucosal resection with a ligation device. World J Gastrointest Endosc 2017; 9: 70-76

[9] Choi CW, Kang DH, Kim HW et al. Comparison of Endoscopic Resection Therapies for Rectal Carcinoid Tumor: endoscopic submucosal dissection versus endoscopic mucosal resection using band ligation. J Clin Gastroenterol 2013; 47: 432-436

[10] Ponugoti PL, Rex DK. Perforation during underwater EMR. Gastrointest Endosc 2016; 84: $543-544$ 